\title{
"It's making contacts": notions of social capital and implications for widening access to medical education
}

\author{
S. Nicholson ${ }^{1}$ (D) J. A. Cleland ${ }^{2}$
}

Received: 2 August 2016/Accepted: 31 October 2016/Published online: 14 November 2016

(C) The Author(s) 2016. This article is published with open access at Springerlink.com

\begin{abstract}
In the UK widening access (WA) activities and policies aim to increase the representation from lower socio-economic groups into Higher Education. Whilst linked to a political rhetoric of inclusive education such initiatives have however failed to significantly increase the number of such students entering medicine. This is compounded by a discourse that portrays WA applicants and students as lacking the essential skills or attributes to be successful in medical education. Much of the research in this area to date has been weak and it is critical to better understand how WA applicants and students negotiate medical admissions and education to inform change. To address this gap we amalgamated a larger dataset from three qualitative studies of student experiences of WA to medicine (48 participants in total). Inductively analysing the findings using social capital as a theoretical lens we created and clustered codes into categories, informed by the concepts of "weak ties" and "bridging and linking capital", terms used by previous workers in this field, to better understand student journeys in medical education. Successful applicants from lower socio-economic groups recognise and mobilise weak ties to create linking capital. However once in medical school these students seem less aware of the need for, or how to create, capital effectively. We argue WA activities should support increasing the social capital of under-represented applicants and students, and future selection policy needs to take into account the varying social capital of students, so as to not overtly disadvantage some social groups.
\end{abstract}

Keywords Lower socio-economic groups · Meritocracy · Social capital · Undergraduate medical education - Under-representation - Weak ties, bridging and linking capital .

Widening access

S. Nicholson

s.nicholson@qmul.ac.uk

1 Institute of Health Science Education, Barts and The London School of Medicine and Dentistry, Queen Mary University of London, 3rd Floor Garrod Building, Turner Street, Whitechapel, London E1 2AD, UK

2 Division of Medical and Dental Education, University of Aberdeen, Polwarth Building, Foresterhill AB25 2ZD, UK 


\section{Introduction}

People from certain groups, such as those from disadvantaged backgrounds or certain ethnic and cultural groups remain under-represented in medicine worldwide. Despite overt differences in which groups are targeted for increasing representation within medicine, low economic and/or social position relative to others is often the shared underlying issue (e.g. Bowes et al. 2013; Gale and Parker 2013). The reasons for this are linked to a myriad of wider, intersecting systemic and societal issues such as parental education (e.g. EspingAndersen 2004); social influences and expectations (e.g. Howard 2002); individual aspirations (e.g. Keane 2011, Southgate et al. 2015); and prior educational attainment (e.g. Gale and Parker 2013).

Widening access (WA) refers to increasing the fairness of the selection processes and policies that act as a gateway to Higher Education and within the context of this paper aim to increase the number of students from lower socio-economic backgrounds entering medical education (Nicholson and Cleland 2015). Although the issues in WA to medicine are complex, the solutions proposed have often been relatively simplistic. Structural changes such as using contextualised admissions (e.g. Powis et al. 2007) and/or pipeline programmes/WA activities (e.g. Nicholson and Cleland 2015), that help the most able socio-economic under-represented applicants into medicine by addressing any perceived educational disadvantages have been considered sufficient to help these non-traditional students get into medical school and on in medicine. However this meritocratic approach (Sheeran et al. 2007) has generally not been effective-the numbers of applicants from some under-represented groups entering medicine have not changed notably (e.g. Association of American Medical Colleges 2011; BMA 2009; Cleland et al. 2012). This lack of success may reflect the limits of an approach which does not acknowledge (or begin to address) the complex sociological issues which may act as barriers to "getting in" and "getting on" in medical school (Millburn 2012) and which risks "pathologising" nontraditional students as lacking the essential skills, attributes or knowledge to be successful in medical education (Brosnan and Turner 2009; Reay 1998).

However, some applicants from WA backgrounds do successfully negotiate the complex medical admissions process, enter medical school and graduate into postgraduate training. What can we learn from these students that would facilitate WA? Do they struggle once in medical school or is disadvantage no longer apparent (as is assumed in the meritocratic model; Sheeran et al. 2007)? Some recent quantitative studies indicate that disadvantage may in fact continue (Cleland et al. 2015; Stegers-Jager et al. 2015), and there are studies of the aspirations of school pupils from disadvantaged areas/schools (Greenhalgh et al. 2004; Southgate et al. 2015), but there are relatively few empirical studies which move "beyond the numbers" (Baxter et al. 2015), from the macro to the micro, to explore the experiences of people from WA backgrounds who are either actively considering applying for medical school or have achieved a place at medical school. However, understanding the experiences of these individuals is critical to driving change in the philosophies, policies and practice of WA.

We drew on the theoretical models of social capital to understand how individuals access and create resources, or struggle to, which enable them to be successful within medical admissions and education. The main exponents of social capital theory are Bourdieu (1986), Coleman (1988) and Putnam (2000). Bourdieu's theories and concepts are gaining popularity in medical education (e.g. Balmer et al. 2015; Brosnan 2009; Varpio and Albert 2013) and in the literature on WA to medicine (e.g. Razack et al. 2015). 
However, some view Bourdieu's emphasis on the embodied nature of capital, with its subjugation of personal agency, as a means of understanding perpetuating embedded social inequalities rather than providing support for social change (Alexander 1995; Bourdieu and Wacquant 1992). Given social mobility is the ultimate goal of WA to medicine (e.g. Carrasquillo and Lee-Rey 2008; Millburn 2012), we further draw on Granovetter's (1973) earlier work on "weak ties" which "provide people with access to information and resources beyond those available in their own social circle" (Granovetter 1983, p. 209), and Putnam's (2000) concepts of bridging (expanding networks) social capital. This is also reflected in what Halpern (2005) refers to as linking capital, which enables vertical connections to be made between those in different power positions. Weak ties, bridging and linking capital provide the potential to make connections beyond one's immediate social network, to reach out beyond the familiar, "to generate outcomes which are valued" (Croll 2004, p. 398).

In this paper, we aimed to explore the notion of social capital at a micro (individual) level, how it is created, the different forms it takes, and how it works (Putnam 1995; Fuller et al. 2011) in relation to opening up new opportunities for medical applicants and students from lower socio-economic groups. Following Bateson (1984) and Moore (2007), that data as resources are reflexively constructed within research processes rather than existing independently of these, we used data from three separate qualitative studies of our own as collective evidence from which to draw inferences relevant to the research question (Hammersley 2010). Each study focused on the same central issue, of WA to medicine within the UK context, but explored this in different groups of participants. Our aim in analysing this data collectively was to gain new insight, via "snapshots", into the ways in which medical school applicants and medical students from WA backgrounds negotiate accessing information and resources in order to successfully apply to, and progress through, medical school.

\section{Methods}

Working from an interpretivist perspective, that there are multiple realities because meaning is grounded in experience and reality is context-dependent, we drew on data collected using qualitative approaches (e.g. Carter and Little 2007). Each study is described briefly to provide context and give an indication of the trustworthiness and authenticity of the data (Lincoln and Guba 1985; Guba and Lincoln 1994), and to illustrate how the three studies are sufficiently congruent to enable cross comparisons and insight generation across studies.

\section{Study A (Cleland and Nicholson 2013)}

A 3 focus group study of 19 senior secondary (high) school students and/or foundation students on WA programmes, which aimed to explore the issues that medical applicants from disadvantaged backgrounds face, and what initiatives they find useful. The school students came from Inner City schools based in areas of high social deprivation/low participation in HE rates, while the foundation students were on Year Zero of an extended medical degree with stringent socio-economic eligibility criteria. Each focus group followed the same semi-structured interview guide to stimulate discussion around participants' experience of applying for medicine, any specific difficulties they experienced or perceived, and what help, if any, formal or otherwise, they found useful. 


\section{Study B (Cleland and Medhi 2015)}

An interview study with 14 first year medical students from two urban medical schools in Scotland, who described themselves as from socio-economically disadvantaged backgrounds, under-performing schools and/or first in family to go to medical school. The aim of this study was to explore the individual and social factors which contributed to them "getting into" medicine. Interviews followed a similar semi-structured interview guide to that described for Study A, with the addition of questions about their experiences of medical school to date.

\section{Study C (Nicholson 2013)}

A mixed methods (focus groups and 15 follow-up individual interviews) study with senior (clinical years) medical students carried out in 2011-2012 exploring their perspectives concerning the academic experience of WA students, with particular reference to their models of learning and professional development. This study's focus group participants were from varied socio-economic backgrounds whilst the majority of individual interviews were with students who identified themselves as coming from "working class" or "nontraditional" backgrounds. The National Statistics Socio-economic Classification (NS-SEC) of these participants confirmed they came from under-represented socio-economic groups.

In each study, after obtaining research ethics as per local requirements, written consent was sought from participants and focus groups/interviews were recorded with permission. All interviews were anonymised and transcribed.

Each study was originally analysed individually, with the primary findings relating to barriers and facilitators of the medical admissions process (Cleland and Nicholson 2013), resilience (Cleland and Medhi 2015) and socio-cultural models of learning and professional development (Nicholson 2013). However, when discussing them in relation to each other, we realised that there were additional discoveries which would be illuminated by putting the three data sets in conversation with each other. Only by doing this could we gain insight into the precise role of social capital at different stages of medical admissions and education. Thus, we combined data from the three studies for secondary analysis, the first step of which was a primary level thematic framework analysis (Ritchie and Spencer 1993) of the larger, collective data set.

This analysis enabled us to identify key themes around participants' views and experiences, and to develop a coding framework. Analysis progressed via face-to-face meetings, telephone discussions, and email where ongoing coding and comparisons, similarities and differences in experiences, were explored and debated. After the themes emerged, and following further discussion, we extended beyond thematic analysis, using notions of social capital to critically examine how medical applicants and students from lower socioeconomic groups access information and resources, or struggle to do so, to achieve desired outcomes. Specifically, Granovetter's (1973) concept of “weak ties” and Halpern's (2005) linking capital had resonance with our data and provided greatest explanatory power. Thus, we used these concepts to define the theoretical lens of social capital with which to conceptualise the data and relate our findings to the wider context of medical education. The use of this lens enabled us to analyse how "non-traditional" medical school applicants and students (who are weakly positioned in terms of social capital compared to "traditional" medical applicants and students, who are firmly embedded in the dominant social 
group-(e.g. Hafferty 1988) create bridges beyond their immediate social networks, to reach out beyond the familiar, and open up new opportunities.

Qualitative research and analysis are dependent on the relationship between researcher and the research process (e.g. McMillan 2015). Thus, we considered our positions and relationships with the data constantly and critically, bearing in mind our different disciplinary backgrounds ( $\mathrm{SN}$ is a medical doctor, JC a psychologist), research interests (a mutual interest in selection and widening access, but often working from different theoretical perspectives and with preferences for different methodological approaches) and personal life courses (Giele and Elder 1998), and how these might have shaped our coconstruction of the data.

\section{Results}

We present three themes in this section, which together provide insight into the journey of students from under-represented socio-economic groups through the medical admissions process and medical school. To provide representation of the dataset and aid validity please note that all quotes are from different participants.

\section{On lacking the necessary contacts or resources}

This was an important theme drawing consensus from all participants with data clearly illustrating that participants' shared understanding was that their "social capital" (our phrase) was low, lower than what they considered was available to their reference group (Merton 1957), i.e. applicants from more advantaged backgrounds and/or medical families:

I think it's sometimes a little unfair for people who do have contacts... unfair for us who don't compared to them. Because if you've got dad who's a paediatric consultant, you're obviously going to get a placement in paeds. But if you don't know anyone who's a doctor, you have to do it all yourself. (First year medical student from lower socio-economic background)

I went to the summer school and everyone there is really middle class. Most of them went to private schools. Two of the girls, their fathers were surgeons and professors and so on. You think, wow. You really see yourself in relation to other people. (High school student/applicant to medicine from lower socio-economic background).

All participants (applicants, early years' students, more senior students) discussed how they struggled to access support and resources compared to more advantaged students:

Interviewee I think there've been a lot of hurdles, every time, applications to get into medical school, and your first couple, your first exams, every final exams, your OSCEs and your, any deadline really, it has always been more of an effort on my part to reach out to people, to get any help that I can get, maybe compared to some people who are from a lot much better backgrounds, who can access those resources a lot easier

Interviewer and why is it easier for the ones who have different backgrounds? 
Interviewee I sort of always feel like, I'm having to discover all these things for myself, and my college friends as well, I think, we are sort of from the same background, I said that two of them haven't got doctors in the family, we're discovering things for ourselves.(Clinical medical student from lower socioeconomic background)

This student highlights two main issues. First, that he believes he is disadvantaged in accessing educational resources compared to other students who he describes as from better backgrounds and with doctors in the family. Second, that he isn't alone-he associates with other students from similar backgrounds experiencing the same difficulties. We do not know, however, if our participant sees himself as so tightly bonded with this group that he neglects, or cannot make connections, with medical students from more privileged backgrounds.

\section{On social capital, widening access initiatives and other sources of information}

Participants framed their descriptions of their experiences of WA initiatives in terms of how such participation was perceived to increase their social capital. For example, the following except from a focus group discussion describes how medical student mentors helped with application preparation and illustrates the utility of a WA initiative in terms of bridging and linking capital:

PAR5 I remember one session, that was highly enlightening, they give you a personal mentor who is a medical student and there was lots of help with work experience, with applying for entrance tests and with writing a personal statement, so I guess that is a bit more accessible

MOD Has anyone else had this sort of help?

PAR1 We have had ex medical students coming into our school and they have sort of helped us through, helped us around work experience, helped us with the application process really and that has made big differences to the path for medical applicants. (High school medical applicants from inner city schools with low participation rates)

Students preparing to apply for medicine valued the contact with current medical students who bridged the gap between the world and the experiences of these applicants from lower socio-economic groups, who had limited or no contact with medical personnel or the medical world (with its perceived advantages in knowing how to successfully complete a medical school application) until then. With reference to Granovetter's (1973, 1983) work, these medical student mentors represent "weak ties" as they, as described, are outside the participants' usual social circles, and have no established or long-lasting relationship with the participants.

The previous quotation was typical: our focus group participants and the early years medical students gave many examples of bridging and linking social capital associated with WA initiatives as the following additional two quotations indicate:

Not only is it a friendly face but they know more than anyone how intense it is and also the mentor I had, she used to sit on the interview panels quite often and because of the position she was in, she was volunteering me advice and anything else to stick on my application. I could speak to her and she definitely pointed me in the right direction. (Focus Group participant from inner city school/low participation area)

I think it's a big issue when you come from a poorer background you don't have the network of people who can advise you. You don't know any doctors. You don't 
know anybody who's actually maybe gone to university before other than your teachers at school who only have a very short period to talk to you. So it's very hard to arrange all of these extras that you need to get into medical school. (Medical school applicant from lower socio-economic group)

Unfortunately the data also illustrates that not all applicants/potential applicants were able to access these initiatives, thus missing out on bridging and linking social capital:

I think that there was almost like a post code lottery idea with it as well, as far as I was aware, where there was a school that's really maybe two miles down the road from me, both local authority schools, and because the proportion of people they were sending to university was less than our school, our school just was above the threshold for qualifying for whatever support was available. They had UKCAT workshops, people came down from UKCAT, from the medical schools, to talk to them, and we just felt neglected when we were a couple of miles up the road but in exactly the same position. (Medical applicant self-identifying from lower socio-economic group)

Interestingly, there were also examples of increasing resources via the internet (Warschauer 2003):

I went trawling through the student room and I found this golden nugget. It was this list, it was on some random thread. And it was this list of all of the people in London hospitals that were willing to give work experience to Year 12 students. Amazing. It had all of the hospitals on it and the numbers and the emails. I thought I was in heaven. (Medical applicant from lower socio-economic group)

The Internet can be a convenient and efficient means of maintaining existing social ties and/or of creating new virtual ties (e.g. Pénard and Poussing 2010) as in this example where any student with access to the internet can join "the student room" (on-line chat room) and connect with other medical applicants and students, including those from other social groups, and access information which may traditionally have been available only to particular social groups.

\section{On knowing what is important}

Our data illustrates the effectiveness of such relationships which facilitate upward mobility by forging linking social capital between WA applicants and students and those people and groups occupying higher power positions. The following interview excerpts from medical students from disadvantaged backgrounds illustrate that they recognise the need to form such relationships to progress.

Interviewee I haven't had so many resources and so much help as I've not had people like family friends or doctor friends in my family or anything like that. I've never really had access to people who could give me experienced advice. I've not had those resources. There's students in our year who I know, who know admissions tutors or their parents know admissions tutors and for me that's just like crazy cos there's no way I'd be able to access that. So you do have to try and fit in firstly and secondly it is more of a struggle to get to those same resources as it really does mean going out of your way (clinical medical students from lower socio-economic group) 
The second following example comes from a graduate who as an applicant to medicine used his weak ties with a hospital doctor to obtain work experience:

I was working as a healthcare assistant and I asked one of the consultants on the ward if he'd be willing to let me shadow him and he'd agreed to that. (First year medical student who self-identifies as coming from a lower socio-economic group)

Furthermore, it seemed from the data that our medical students, who admittedly represent those small numbers of WA students who get into medicine, had less difficulty understanding what they needed to be successful in the admissions process (e.g. get the necessary academic grades, do the admissions test, have evidence of work experience) than they did in accessing the arguably more intangible resources necessary to progress once in medicine.

Interviewer I mean are there any aspects of clinical medical education which students who come from, and you describe it as a bad background, would struggle more with, than students who come from a more privileged background?

Participant I think it's making contacts

Interviewer contacts with, with whom?

Participant Socialising, I mean making friends higher up, because it's not something that you'd like to say but with medicine there is a lot of knowing your consultants well, and knowing your future employers, and some people from the get go, kind of know that

Interviewer On day to day interaction with staff on the wards, do you think generally speaking things are equal?

Participant No it's not equal. I think probably interaction is better with people like traditional medical students and not as good for the non-traditional medical students

Interviewer But why?

Participant I always go back to the way people speak but it's important because that's the first thing, that's one of the first things you notice about people the way they speak, so, I think the way people speak and kind of discussions they have with people, and obviously the doctors, they're more likely to be from a traditional background as well. (Clinical medical student from higher socio-economic group commenting on his observations of his peers from lower socio-economic groups)

So, although students from under-represented groups now form a small proportion of the "medical world" effectively engaging and making advantageous relationships does not seem to come easily and remains an issue. Moreover, whilst they may struggle in engaging with faculty at the level of forming linking social capital, the following participant raises a further vital issue in that some medical students from disadvantaged backgrounds may not even be aware of the benefits of doing so and hence miss opportunities to increase their social capital.

Interviewer Interviewee
What do you think about the networking with staff?

I don't really do much of it, partly because I never valued it, because I didn't think it was important, and partly because I had no direction, I've kind of started to do it more now. I find that sort of non traditional students, the reason that they're not good at is because they don't value it, because they don't take it as important as traditional students 
Interviewer Rather than having any difficulties doing it?

Interviewee No, I think it's a mixture of both, because they don't value it, then they have difficulty doing it, and I guess maybe the traditional students are aware of the advantages of networking, and so they feel that they have to do it, and so they work at it, and they get better at it.(Clinical student from lower socioeconomic group)

These issues of unawareness, lack of ease and skill at increasing social capital both bridging and linking whilst at medical school, indicates that WA medical students may have a different experience of medical school than their more advantaged peers, who appear to instinctively understand and value the benefits of increasing social capital at all levels.

\section{Discussion}

Our data provides evidence of significant disadvantage for some students from lower socioeconomic groups either within their applications and/or during their undergraduate studies. Raising awareness of this is important as medical schools with their inherent preference for meritocracy may not recognise such inequality (Reay 1998; Lin 1999). Applying a social capital lens to our secondary analysis of a larger amalgamated dataset has enabled us to think in a more nuanced way about the types of social capital and how possessing social capital facilitates access to valuable information and resources for both medical applicants and students.

Clearly those early in the journey of medical admissions and school, who lacked the social resources of traditional medical students, recognised the importance of using weak ties and linking opportunities to create social capital (Croll 2004). The data suggests however that, once at medical school, such students may fail to recognise the need for, and/ or struggle to negotiate access to the same resources as traditional medical students. It seemed that, while they were aware that "who you know", even where these ties were weak, was influential at the application and admissions stage, they seemed less aware of their need for "upwards" networking and expanding their social circles during medical school, perhaps because the outcomes from relational contacts are less explicit or less immediate. Moreover, as found in earlier studies (Brown and Garlick 2007), they may feel handicapped by their reduced opportunities for social relationships with people that can help them access valuable resources. For some under-represented students, socialising and networking opportunities may take a lower priority than other extra-curricular activities such as paid work, family time and religious practices (Stuart et al. 2011).

Our theory-driven analysis of a large, amalgamated qualitative dataset sought to introduce innovation and add methodological rigor to qualitative research in this field, which has been limited by small, often descriptive studies until relatively recently. Our dataset encompassed applicants to medicine, early years' and later years' students, from seven different medical schools located throughout Scotland and England, representing large urban schools and those located in smaller cities. The re-use and combining of qualitative datasets for generating new knowledge or hypotheses is well-established in other fields (e.g. Hinds et al. 1997). However, there are methodological considerations which we were careful to negotiate. For example, whilst we re-used data which had specifically been generated to address different primary WA research questions to our current focus, the nature of the questions remained similar. The data sets were our own so 
we had sufficient contextual knowledge of the participant groups and involvement in the processes of data collection and analysis (e.g. Parry and Mauthner 2005; van den Berg 2005). We reported, within word limits, sufficient details of the original study and data collection procedures, together with a description of the processes involved in categorising and summarising the data for the secondary analysis (Thorne 1994, 1998).

This study has implications for practice, policy and research. The helpful heuristics of bridging and linking social capital and its associated weak ties enable us to reconceptualise our WA initiatives considering how best to facilitate students accessing the information and resources they value, and need. Similarly, it may be helpful to consider interventions for medical students which bring to their attention ways of strengthening their social capital (Oakley 1991; Stuart et al. 2011). If we are serious about increasing the numbers of students from lower socio-economic groups entering and succeeding in medicine, then we are beholden to examine what Woolcock (1998, p. 185) calls the synergy between "bottom-up capacity and top down resources" highlighting the importance of creating a "dynamic and cooperative relationship" between the macro (institution) and micro (individuals). Such a relationship, for example, would seek opportunities for a more egalitarian use of resources and collaborative removal of barriers, which contrasts with widely accepted medical models of WA provision that are based on "topping up" or "raising aspirations" of students from atypical backgrounds who are seen as deficient, and "pathologising" medical students from disadvantaged backgrounds rather than valuing their difference. By this, we mean appreciating that having a diverse student body may actually bring value to the medical school and ultimately patient care (Laveist and NuruJeter 2002; Deas et al. 2012). Initiatives therefore that encourage and value specific team, community, and paid as well as voluntary work experience, alongside traditional medical work experience, are more accessible to students from under-represented groups. National schemes that offer access to medical work experience transparently rather than by a process of "who you know" and more equitable access outreach activities are in the process of development (Selecting for Excellence Executive Group 2014). Our findings confirm that facilitating bridging capital between applicants and students from lower socio-economic groups and medical students acting either formally or informally as mentors is of great value in building social capital. It is emphasised that supporting the social capital of these students once in medical school should not be neglected. These aims present a significant challenge for an enduring traditional medical culture resistant to change that currently ignores the value of the differential social capital of students from under-represented groups. Curriculum innovation that sensitively maximises the skills, knowledge and resilience of these students may contribute significantly to shaping the future medical workforce.

We would envisage further research and innovation to develop a more egalitarian medical selection policy that relies less on traditional academic achievement and interviewing by expert panel to include selection tools such as MMI and SJTs which, though not fully evaluated in medical selection as yet, have potential to not disadvantage candidates from lower socio-economic groups (Lievens 2013; Patterson et al. 2016). Similarly in best serving healthcare needs by recruiting doctors to work in rural and inner city areas exploring selection tools with added-value that are not predicated on underpinning social capital may be beneficial (Girotti et al. 2015).

In terms of research, a longitudinal study would provide opportunities to explore temporal changes (Giele and Elder 1998) in individuals' use of weak ties and linking capital across personal journeys through medical education and training. It may also be useful to consider the stories of those doctors from widening access backgrounds, 
reflecting back on their journeys in medical education and training, as these may provide useful information on career trajectories and for informing change.

In conclusion, by developing such a framework of social capital, we suggest that some applicants and students from lower socio-economic groups within UK medical education experience persistent disadvantage. This has significant implications for both medical selection and education. Reconceptualising effective WA as opportunities for providing bridging and linking social capital encourages those committed to diversifying the medical workforce and democratising medical education to consolidate, and focus on activities and policies that effectively support increasing the social capital of all under-represented students.

Acknowledgements Our thanks to the Medical Schools Council (MSC) of the UK for funding Study A; REACH Scotland for funding Study B; and Queen Mary University of London, and to the medical school applicants and students who gave their time to be interviewed. Our thanks also to Dr Sean Zhou and Dr Sally Curtis, and Manjul Medhi, for their help with data collection for studies A and B respectively. Our thanks also to Dr Lara Varpio, Uniformed Services University of the USA, for her advice and guidance on collating data sets and her comments on the draft manuscript.

Author contributions JAC and SN conceived the original idea for this research, jointly carried out the secondary data analysis, and co-prepared the manuscript drafts. Both authors contributed to the critical revision of the paper and approved the final manuscript for submission.

Open Access This article is distributed under the terms of the Creative Commons Attribution 4.0 International License (http://creativecommons.org/licenses/by/4.0/), which permits unrestricted use, distribution, and reproduction in any medium, provided you give appropriate credit to the original author(s) and the source, provide a link to the Creative Commons license, and indicate if changes were made.

\section{References}

Alexander, J. C. (1995). Fin de siecle social theory: relativism, reduction, and the problem of reason. London; New York: Verso.

Balmer, D. F., Richards, B. F., \& Varpio, L. (2015). How students experience and navigate transitions in undergraduate medical education: an application of Bourdieu's theoretical model. Advances in Health Sciences Education, 20, 1073-1085.

Bateson, N. (1984). Data construction in social surveys. London: Allen and Unwin.

Baxter, C., Baxter, D., \& Baxter, M. (2015). Widening participation in medicine: moving beyond the numbers. Medical Education, 49, 15-17.

Bourdieu, P. (1986). The forms of capital. In J. G. Richardson (Ed.), Handbook of theory and research for the sociology of education (pp. 241-258). New York: Greenwood Press.

Bourdieu, P., \& Wacquant, L. (1992). An invitation to reflexive sociology. Chicago: University of Chicago Press.

Bowes, L., Thomas, L., Peck, L., \& Nathwani, T. (2013). International research on the effectiveness of widening participation. London: Higher Education Founding Council for England (HEFCE). Retrieved Sept 29, 2015 from http://www.hefce.ac.uk/pubs/rereports/year/2013/wpeffectiveness/.

British Medical Association. (2009). Equality and diversity in UK Medical Schools. London: British Medical Association. Retrieved Sept 29, 2015 from http://bma.org.uk/developing-your-career/medicalstudent/equality-and-diversity-in-medical-schools.

Brosnan, C. (2009). Pierre Bourdieu and the theory of medical education: Thinking "relationally" about medical students and medical curricula. In C. Brosnan \& B. S. Turner (Eds.), Handbook of the sociology of medical education (pp. 51-68). Oxon and New York: Routledge.

Brosnan, C., \& Turner, B. S. (Eds.). (2009). Handbook of the sociology of medical education. Oxon and New York: Routledge.

Brown, G., \& Garlick, P. (2007). Changing geographies of access to medical education in London. Health and Place, 13(2), 520-531. 
Carrasquillo, O., \& Lee-Rey, E. T. (2008). Diversifying the medical classroom: is more evidence needed? JAMA, 300, 1203-1204.

Carter, S. M., \& Little, M. (2007). Justifying knowledge, justifying method, taking action: epistemologies, methodologies, and methods in qualitative research. Qualitative Health Research, 17, 1316-1328.

Cleland, J., Dowell, J., McLachlan, J., Nicholson, S., \& Patterson, F. (2012). Identifying best practice in the selection of medical students. London: General Medical Council. Retrieved Dec 01, 2015 from http://www.gmc-uk.org/Identifying_best_practice_in_the_selection_of_medical_students.pdf_51119804. pdf.

Cleland, J.A. \& Medhi, M. (2015). Optimism and grit: Key to success in the widening access student's journey into medical school? Research Paper presented at the Association for Medical Education Europe (AMEE) Annual Conference, Sept 5-9th Glasgow, UK.

Cleland, J.A., \& Nicholson, S. (2013). A review of current practice to support Widening Participation in medicine. London: Selecting for Excellence Group (SEEG). Retrieved Dec 01, 2013 from http://www. medschools.ac.uk/Publications/Documents/MSC-Selecting-for-Excellence-End-of-year-report.pdf.

Cleland, J.A., Nicholson, S., \& MacKenzie, R.K. (2015). Medical students from lower socio-economic backgrounds do less well on the Foundation Programme selection process. An invited presentation at the NHS Education for Scotland (NES) Medical Directorate Annual Conference, April 20-21st 2015, Edinburgh.

Coleman, J. C. (1988). Social capital in the creation of human capital. American Journal of Sociology, 94, 95-120.

Croll, P. (2004). Families, social capital and educational outcomes. British Journal of Educational Studies, 52, 390-416.

Deas, D., Pisano, E. D., Mainous, A. G., Johnson, N. G., Singleton, M. H., \& Gordon, L. (2012). Improving diversity through strategic planning: a 10-year (2002-2012) experience at the medical university of South Carolina. Academic Medicine, 87(11), 1548-1555.

Esping-Andersen, G. (2004). Untying the Gordian knot of social inheritance. Research in Social Stratification and Mobility, 21, 115-138.

Fuller, A., Heath, S., \& Johnston, B. (2011). Rethinking widening participation in higher education: the role of social networks. London: Routledge.

Gale, T., \& Parker, S. (2013). Widening participation in Australian Higher Education. Report to the Higher Education Funding Council for England (HEFCE) and the Office of Fair Access (OFFA). England: CFE (Research and Consulting) Ltd, Leicester UK and Edge Hill University, Lancastershire. Retrieved Dec 01, 2015 from http://www.deakin.edu.au/arts-ed/efi/pubs/wpin-australian-he.pdf.

Giele, J. Z., \& Elder, G. H. (1998). Methods of life course research: Qualitative and quantitative approaches. Thousand Oaks, CA: Sage.

Girotti, J. A., Park, Y. S., \& Tekian, A. (2015). Ensuring a fair and equitable selection of students to serve society's health care needs. Medical Education, 49(1), 84-92.

Granovetter, M. (1973). The strength of weak ties. American Journal of Sociology, 78, 1350-1380.

Granovetter, M. (1983). The strength of weak ties: a network theory revisited. Sociological Theory, 1, 201-233.

Greenhalgh, T., Seyan, K., \& Boynton, P. (2004). "Not a university type": focus group study of social class, ethnic and sex differences in school pupils' perceptions about medical school. British Medical Journal, $328,1541-1544$.

Guba, E., \& Lincoln, Y. (1994). Competing paradigms in qualitative research. In N. K. Denzin \& Y. S. Lincoln (Eds.), Handbook of qualitative research (pp. 105-117). Thousand Oaks, CA: Sage.

Hafferty, F. W. (1988). Cadaver stories and the emotional socialization of medical students. Journal of Health and Social Behaviour, 29, 344-356.

Halpern, D. (2005). Social capital. Cambridge: Polity Press.

Hammersley, M. (2010). Can we re-use qualitative data via secondary analysis? Notes on some terminological and substantive issues. In P. Atkinson \& S. Delamont (Eds.), Qualitative research methods (pp. 199-212). Thousand Oaks: Sage Publications Inc.

Hinds, P. S., Vogel, R. J., \& Clarke-Steffen, L. (1997). The possibilities and pitfalls of doing a secondary analysis of a qualitative data set. Qualitative Health Research, 7, 408-424.

Howard, T. (2002). "A tug of war for our minds": African American high school students' perceptions of their academic identities and college aspirations. High School Journal, 87, 4-17.

Keane, E. (2011). Dependence-deconstruction: widening participation and traditional-entry students transitioning from school to higher education in Ireland. Teaching in Higher Education, 16, 707-718.

Laveist, T. A., \& Nuru-Jeter, A. (2002). Is doctor-patient race concordance associated with greater satisfaction with care? Journal of Health and Social Behavior, 43, 296-306. 
Lievens, F. (2013). Adjusting medical school admission: assessing interpersonal skills using situational judgement tests. Medical Educaton, 47(2), 182-189.

Lin, N. (1999). Social networks and status attainment. Annual Review Sociology, 25, 467-487.

Lincoln, Y., \& Guba, E. (1985). Naturalistic inquiry. London: Sage.

McMillan, W. (2015). Theory in healthcare education research: the importance of worldview. In J. A. Cleland \& S. J. Durning (Eds.), Researching medical education (pp. 15-24). Oxford: Wiley.

Merton, R. (1957). Social theory and social structure. New York: Free Press.

Millburn, A. (2012). Fair access to professional careers. A progress report by the independent reviewer on social mobility and child poverty. Retrieved Sept 29, 2015 from https://www.gov.uk/government/ uploads/system/uploads/attachment_data/file/61090/IR_FairAccess_acc2.pdf.

Moore, N. (2007). (Re)using qualitative data. Sociological Research Online, 12, 3. Retrieved Sept 29, 2015 from http://socresonline.org.uk/12/3/1.html.

Nicholson, S. (2013). Exploring the academic experience of medical students coming from a non-traditional socio-economic background. A study of their models of learning and professionalization within an undergraduate medical curriculum. Unpublished Doctorate Thesis, Institute of Education, University of London.

Nicholson, S., \& Cleland, J. A. (2015). Reframing research on widening participation in medical education: using theory to inform practice. In J. A. Cleland \& S. J. Durning (Eds.), Researching medical education (pp. 231-244). Oxford: Wiley.

Oakley, P. (1991). Projects with people: The practice of participation in rural development. International Labour Organisation, Geneva. Retrieved Sept 19, 2015 from http://collections.infocollections.org/ ukedu/en/d/Jh2507e/.

Parry, O., \& Mauthner, N. S. (2005). Back to basics: who re-uses qualitative data and why? Sociology, 39, 337-342.

Patterson, F., Knight, A., Dowell, J., Nicholson, S., Cousans, F., \& Cleland, J. (2016). How effective are selection methods in medical education and training? Evidence from a systematic review. Medical Education, 50(1), 36-60.

Pénard, T., \& Poussing, N. (2010). Internet use and social capital: The strength of virtual ties. Journal of Economic Issue, 44, 569-595.

Powis, D., Hamilton, J., \& McManus, I. C. (2007). Widening access by changing the criteria for selecting medical students. Teaching and Teacher Education, 23, 1235-1245.

Putnam, R. D. (1995). Tuning in, tuning out: The strange disappearance of social capital in America. Political Science and Politics, 28, 664-683.

Putnam, R. D. (2000). Bowling alone: The collapse and revival of American Community. New York: Simon and Schuster.

Razack, S., Hodges, B., Steinart, Y., \& Maguire, M. (2015). Seeking inclusion in an exclusive process: discourses of medical school student selection. Medical Education, 49, 36-47.

Reay, D. (1998). 'Always knowing' and 'never being sure': Familial and institutional habituses and higher education choice. Journal of Educational Policy, 13, 519-529.

Ritchie, J., \& Spencer, L. (1993). Qualitative data analysis for applied policy research. In A. Bryman \& R. Burgess (Eds.), Analysing qualitative data (pp. 173-194). London: Routledge.

Selecting for Excellence Executive Group (SEEG). Selecting for excellence: final report. (2014). London: Medical Schools Council. Retrieved April 22, 2014 from http://www.medschools.ac.uk/ SiteCollectionDocuments/Selecting-for-Excellence-Final-Report.pdf.

Sheeran, Y., Brown, B. J., \& Baker, S. (2007). Conflicting philosophies of inclusion: The contestation of knowledge in widening participation. London Review of Education, 5, 249-263.

Southgate, E., Kelly, B. J., \& Symonds, I. M. (2015). Disadvantage and the 'capacity to aspire' to medical school. Medical Education, 49, 73-83.

Stegers-Jager, K. M., Steyerberg, E. W., Lucieer, S. M., \& Themmen, A. P. N. (2015). Ethnic and social disparities in performance on medical school selection criteria. Medical Education, 49, 124-133.

Stuart, M., Lido, C., Morgan, J., Solomon, L., \& May, S. (2011). The impact of engagement with extracurricular activities on the student experience and graduate outcomes for widening participation populations. Active Learning in Higher Education, 12, 203-215.

Thorne, S. (1994). Secondary analysis in qualitative research: Issues and implications. In J. Morse (Ed.), Critical issues in qualitative research methods (pp. 263-279). London: Sage Publication.

Thorne, S. (1998). Ethical and representational issues in qualitative secondary analysis. Qualitative Health Research, 8, 547-555.

Van den Berg, H. (2005). Reanalyzing qualitative interviews from different angles: The risk of decontextualization and other problems of sharing qualitative data. Qualitative Social Research, 6, 1. Retrieved Sept, 29, 2015 from http://www.qualitative-research.net/index.php/fqs/article/view/499/1075. 
Varpio, L., \& Albert, M. (2013). AM last page: How pierre bourdieu's theory and concepts can apply to medical education. Academic Medicine, 88, 1189.

Warschauer, M. (2003). Technology and social inclusion: Rethinking the digital divide. Cambridge: MIT Press.

Woolcock, M. (1998). Social capital and economic development: Toward a theoretical synthesis and policy framework. Theory and Society, 27, 151-208. 